\title{
Urgences
}

\section{Gilbert Dupuis, Le cheval de l'île St-Barnabé, Rimouski, Éditeq, 1983. \\ Jacqueline Chénard}

Numéro 8, 4e trimestre 1983

Littérature jeunesse

URI : https://id.erudit.org/iderudit/025126ar

DOI : https://doi.org/10.7202/025126ar

Aller au sommaire du numéro

\section{Éditeur(s)}

Urgences

\section{ISSN}

0226-9554 (imprimé)

1927-3924 (numérique)

Découvrir la revue

Citer ce compte rendu

Chénard, J. (1983). Compte rendu de [Gilbert Dupuis, Le cheval de l'île St-Barnabé, Rimouski, Éditeq, 1983.] Urgences, (8), 117-119.

https://doi.org/10.7202/025126ar

Ce document est protégé par la loi sur le droit d'auteur. L’utilisation des services d'Érudit (y compris la reproduction) est assujettie à sa politique d'utilisation que vous pouvez consulter en ligne.

https://apropos.erudit.org/fr/usagers/politique-dutilisation/
Cet article est diffusé et préservé par Érudit.

Érudit est un consortium interuniversitaire sans but lucratif composé de l’Université de Montréal, l'Université Laval et l'Université du Québec à Montréal. Il a pour mission la promotion et la valorisation de la recherche. https://www.erudit.org/fr/ 


\section{PARUTIONS COMMENTÉES}

LE CHEVAL DE L'ÎLE ST-BARNABÉ, texte de Gilbert Dupuis, illustré par Hélène Couture, EDITEQ, Rimouski, 1983.

Quelques magies, trois ou quatre, au moins, doivent opérer pour qu'un livre plaise à des enfants.

Magie de la couleur, du regard. Dans Le cheval de l'île StBarnabé, on regarde et on voit beaucoup:

Samuel: -"Les images sont belles!"

Anne: -"... des belles couleurs! Sont un peu bizarres les dessins parce que les enfants ont des yeux ronds ronds ronds comme des boules, sont gros..."

Magalie: - "Moi j'les aime les dessins, sont beaux."

Un autre: - "Y'a beaucoup de couleurs, on voit la mer."

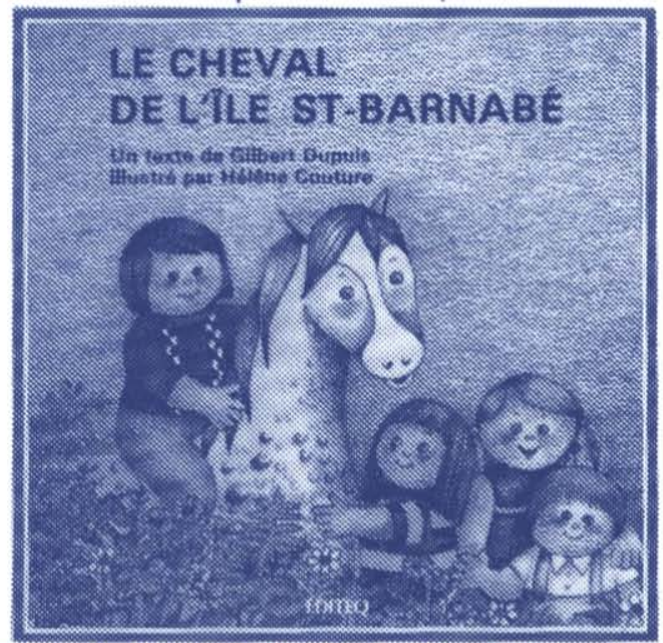

La page centrale en a séduit plus d'un et d'une:

- "C'est beau! J'aime beaucoup beaucoup les pissenlits, moi!"

- "Le cheval a l'air gentil."

- "Dans l'image des framboises, ils sont contents." 
- "On voit des autos".

- "On voit un beau coucher de soleil."

- "Mais j'aime mieux tout en couleur, le noir et blanc, c'est triste."

Magie de l'aventure: marcher sur les cailloux jusqu'au "jardin dans la mer" comme on peut ne marcher que sur les carrés blancs (pas les noirs!), ou sur les lignes du trottoir, comme sur un pont étroit dans la jungle amazonienne, "longtemps, Iongtemps". Arrivés sur les lieux mystérieux, magie de l'exploration et des découvertes: voici des fruits, aes fleurs, des feuilles et des branches dont il ne manque que l'odeur pour fixer correctement l'image (mais peut-on tout demander à un adulte'auteur) et quatre tonneaux pour quatre enfants, et un magnifique cheval gris.

- "Le cheval aurait pu être méchant. II est gentil."

- "Je trouve ça drôle qu'un cheval aide des enfants comme ça, mais j'aime ça..."

- "Le cheval aurait pu être méchant, ils auraient pas pu revenir".

Les éléments dramatiques de I'histoire sont en quelque sorte exorcisés par l'extrême bonhomie du dessin. On sent même quelque fois comme un regret dans les paroles des commentateurs: "Le cheval aurait pu être méchant." Pourvu que tout finisse bien, quoi, on aurait pu avoir plus peur.

Ici l'auteur a le mérite d'inclure dans l'action les phénomènes de la marée et de l'écho, sans qu'on sente d'intention didactique. Chapeau!

Si la vraisemblance du voyage sur l'île, de la découverte des quatre tonneaux, de la rencontre du gentil cheval, de la présence bienveillante de I'homme au début et à la fin de l'histoire n'est jamais contestée, il est évident qu'il "ne faut pas nous la faire".

- "Comment i faisaient pour les attacher les tonneaux sur le dos du cheval, pour qu'i tiennent?"

- "Quand le cheval entre dans l'eau, les tonneaux flotteraient et 
ils ne tiendraient pas sur son dos?"

Et surtout:

- "Comment ça se fait que leurs pantalons ont pas descendu quand ils ont enlevé leurs bretelles?"

Heureusement pour l'auteur, dans une des illustrations on voit que Luc a grand'peine à empêcher son pantalon de tomber. Ouf!

Dans ces commentaires, recueillis auprès d'un groupe d'enfants de 2ième et 3ième année de l'école du Rocher à SacréCoeur, on remarque aussi la satisfaction d'avoir toujours l'image bien située par rapport au texte, et le plaisir de voir les difficultés vaincues par les enfants eux-mêmes grâce à leur ingéniosité. Ajoutons pour les parents que ce beau conte risque surtout de plaire aux enfants de trois à sept ans, qui continueront longtemps après la lecture à se complaire dans la contemplation des images où la couleur l'emporte, tout de même, sur le noir et blanc! Les grands accorderont à l'auteur le mérite de donner une égale importance aux personnages, deux filles et deux garçons, dans I'action et dans les idées, et de sous-entendre, tout au long du récit, qu'on peut leur faire confiance (aux grands).

- "Si on est perdu dans une île, pi qu'on veut retourner à l'autre bord, ça donne une idéel"

Et si on se retrouve un jour, à marée haute, sur l'île StBarnabé, en face de Rimouski, peut-être aura-t-on la joyeuse surprise de rencontrer le beau cheval gris.

Jacqueline Chénard 